\title{
QUALITY CONTROL OF SOME HERBAL PREPARATIONS FROM LIBYAN PHARMACEUTICAL MARKET
}

\author{
A. A. Auzi, F. M. Morghem and S. E. Elgarasdy
}

Quality Control Lab., Faculty of Pharmacy, Elfateh University, Tripoli, Libya

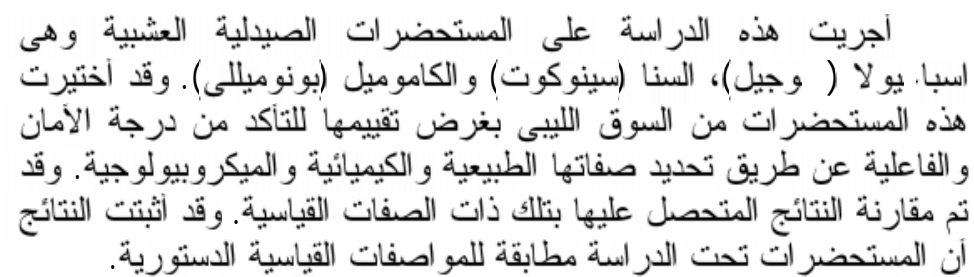

Quality control study was carried out using three pharmaceutical preparations namely, ispaghula Husk (Fypogel), senna (Senokot) and chamomile (Bonomelli) which were selected from Libyan market. This study was carried out to insure their safety and efficacy through determination of their physical, chemical and microbiological characters. The obtained data were compared with standards whenever possible.

It was concluded that the results were in good agreement with the pharmacopoeial standards; therefore these herbal preparations are safe and effective for use.

\section{INTRODUCTION}

The most important factor standing in the way of wider acceptance of herbal drugs is the nonavailability or inadequate standards of checking quality by modern methods. The main reason for the difficulty in developing quality control standards is that most of herbal drugs use the total plant herb or parts of the plant or the use of their total extracts or mixture of plants or mixture of their extracts which may contain a varied number and quantities of chemical constituents.

The analytical control of the plant drugs must take into consideration the fact that the plant material has a complex composition, therefore the analytical limits can not be set as precisely as for the pure chemical 
compound and the composition of the plant drug is influenced by several factors such as age of the plant at collection time, geographical source, harvesting schedules, cultivation techniques, storage period, conditions, activity, stability of active compounds and product purity.

To eliminate some of the causes of inconsistency we should use cultivated plants rather than wild plants; therefore all these factors make standardization of herbal medicinal products is a difficult task. $^{1-4}$

In this study the quality control of herbal selected preparations were determined by different physical, microscopical, chemical and microbiological analysis.

\section{EXPEIMENTAL MATERIALS AND METHODS}

\section{Equipments}

Detection of aflatoxin was carried on Vicam Afla test instrument at quality control laboratory, Faculty of Pharmacy, El- Fateh University of Tropoli.

Heavy metal contamination was recorded on Inductive Couples Spectroscopy (ICP) and mercury analyzer instrument.

\section{Plant material}

Three herbal preparations from Libyan pharmaceutical market were used for the determination of their quality control: Ispaghula Husk, Senna and Roman Chamomile.

\section{Specifications of the used drugs}

\section{1- Ispaghula Husk}

Name of the drug: plantago ovata

Forsk (Plantaginaceae).

Part used: seeds.

Batch number: 328001.

Manufacturing date: 10/ 2003.

Expiry date: $10 / 2006$.

Dosage form: coarse powdered drugs. Active constituents: alkaloids, fatty acids (e.g. linoleic, palmitic, stearic, ...), tannins, amino acids, proteins and $10-30 \%$ mucilage on hydrolysis fractions yield D-xylose, L-arabinose and aldobiuronic acid, sugars and fixed oil.

Uses: it possesses demulcent and laxative effects and it is used in treatment of constipation, dysentery, diarrhea and cystitis.

\section{2-Senna}

Name of the drug: cassia angustifolia Vahl (Fabaceae).

Part (s) used: fruit (pods), leaf.

Batch number: 13530002p.

Manufacturing date: 6/2003.

Expiry date: 6/2006.

Dosage form: tablets.

Active constituents: anthraquinone (dianthrone glycosides sennoside A, $\mathrm{B}, \mathrm{C}$ and $\mathrm{D})$, carbohydrates, mucilage, sterols and their glycosides resin and calcium oxalates.

Uses: traditionally used in treatment of constipation due to its cathartic properties (leaf greater than the fruit). N.B. in Libya doctors prescribes the herb for treatment of constipation and the pharmacist dispenses it as OTC drug. 


\section{3- Roman Chamomile}

Name of the drug: chamaemelum nobile L (Astraceae).

Part used: flower heads.

Batch number: 3311.

Manufacturing date:

Expiry date: 11/2007.

Dosage form: tea bags.

Active constituents: $0.4-1 \%$ volatile oil (containing mainly azuline) flavonoids, coumarins, phenolic and fatty acids.

Uses: it possesses carminative, anthelmentic, antispasmodic and sedative properties. It has been used in dyspepsia, nausea, vomiting, anorexia, dysmenorrheal pain and vomiting of pregnancy.

\section{Methods}

Methods currently utilized in evaluating herbs and their extracts include:

\section{Organolyptic evaluation, ${ }^{3,5-7}$}

It represents the simplest, yet the most human, form of analysis. It involves the macroscopic characters of the plant material (Surface, size, odour, colour, taste and occasionally the snap or sound of its structure), and comparing it with reference drug.

\section{Microscopic examination ${ }^{3,6-8}$}

It is indispensable in the initial identification of the herbs as well as in identifying small fragments of crude or powdered herbs.

Diagnostic microscopic features like type of stomata, trichomes, fibers are important in plant drug standardization, also using quantitative microscope for the determination of some parameters like stomatal number, stomatal index and palisade ratio are important in differentiating closely allied species.

Moisture content determination $^{2,4 \& 6}$

Ash values ${ }^{2,4 \& 6}$

Total ash.

Water soluble ash.

Acid insoluble ash

Ash values considered as one of the pharmacopoeial constants which could be used in evaluation of drugs.

\section{Extractive values ${ }^{2,4 \& 6}$}

The determination of watersoluble or ethanol-soluble extractive is used as a means of evaluating the constituents of drugs which are not readily estimated by other means. It provides an indication of the extent of polar, non- polar and medium polarity components present in plant material.

\section{Swelling index ${ }^{2,4 \& 6}$}

One gram from Fybogel was transferred to $100 \mathrm{ml}$ Stoppard cylinder containing $90 \mathrm{ml}$ of water, shake well for 30 second and allow standing for $24 \mathrm{hrs}$, shaking gently three times during this period. Add sufficient water to produce $100 \mathrm{ml}$, mix gently 30 sec, avoiding entrainment of air, and allow standing for $5 \mathrm{hrs}$. and measuring the volume of mucilage, repeat this determination three times and then calculate the average.

\section{Foreign matter ${ }^{2,4 \& 6}$}

Medicinal plants collected should be free from soil, stone dust, insect 
parts, animal excreta or any parts of animals.

\section{Heavy metals contamination ${ }^{2,4,6}$}

The concentration of lead and mercury were measured by Atomic Absorption Spectroscopy and Inductive Coupled Spectroscopy.

Microbial contamination ${ }^{2 \& 6}$

Medicinal plant materials normally carry a high number of bacteria and moulds which are coming from soil and atmosphere as well as bacteria and fungi from the naturally occurring microbial flora of herbs. Handling and production often causes additional contamination and microbial growth. The determination of $E$. coli and moulds may reflect care taken in harvesting and production practice. There may be a need to specify the total count of aerobic microorganisms, yeast and moulds, in addition, mycotoxins contamination should be fully considered.

\section{Aflatoxin test ${ }^{2 \& 9}$}

The substance known as aflatoxins well produce serious side effects if consumed along with the crude drug, it should be completely removed or should not be present. Quantitative and qualitative determination of aflatoxin B1, B2, G1 and $\mathrm{G} 2$ were done according to the AOAC official method program.

\section{RESULTS AND DISCUSSION}

\section{Results and evaluation of Ispaghula Husk}

Ispaghula is used as a bulk forming laxative and the main pharmacological action is due to the mucilage content, where the swelling properties of the mucilage make it absorb water in gastrointestinal canal thereby increasing the volume of feces and promoting peristalsis so it is used in treatment of chronic constipation when excessive straining must be avoided following anorectic surgery or in case of management of diarrhea, this pharmacological action is related to the swelling properties. ${ }^{5}$

All the results of physicochemical tests (organoleptic and microscopical investigations, moisture content, ash value, heavy metal contamination, swelling index and aflatoxin test) show acceptable values which approved in the pharmacopoeia.

Therefore the samples of batch number 328001 of Fybogel which collected from private pharmacy garden in Tripoli are obey with roles of pharmacopoeial standards so the batch is accepted. Results of our work are demonstrated as following:

\section{Organoleptic investigation}

Colour: pale puff.

Odour: characteristic orange odour

Taste: orange like flavour

\section{Microscopical investigation}

Reddish brown endosperm cells, epidermal cells and polygonal Prismatic cells. ${ }^{6-8}$

Moisture content: $0.84 \%$ (normal value not more than $12 \%$ of its weight).

Swelling index: $42.1 \mathrm{ml}$ (normal value not less than $40 \mathrm{ml}$ ). 


\section{Heavy metals contamination}

Lead: $0.412 \mathrm{mg} / \mathrm{kg}$ (normal value of lead in dried herbs $10 \mathrm{mg} / \mathrm{kg}$ ).

Mercury: $0.00516 \mathrm{ppm}$ (normal value of mercury in dried herbs is less than $1.5 \mathrm{ppm})$.

Ash value: $3.6 \%$ (normal value of total ash not more than $4.5 \%$ ).

Aflatoxin test: none detectable amount.

\section{Results and evaluation of senna}

Senna is an anthraquinone stimulant laxative used for the treatment of constipation and for bowel evacuation, after carrying the physicochemical tests as mentioned above we found that our senna samples of batch number 1353002p and was collected from the private pharmacy garden in Tripoli are limits of pharmacopoeial standards for the specification of senna as raw material and therefore the batch accepted for use in pharmaceutical preparatipons. Results of our work are shown as following:

\section{Organoleptic investigation}

Colour: pale green.

Odour: slightly characteristic.

Taste: slightly bitter.

Microscopical investigation: (all characteristic fragments appeared $)^{6-8}$ Non-glandular trichome, paracytic stomata and crystal sheath.

Moisture content: $5.64 \%$ (where normal value not more than $12 \%$ of its weight).

\section{Heavy metals contamination} Lead: $0.475 \% \mathrm{mg} / \mathrm{kg}$.
Mercury: $0.00389 \%$ ppm

(While normal values of lead and mercury in dried herbs are $10 \mathrm{mg} / \mathrm{kg}$ and $1.5 \mathrm{ppm}$ respectively).

\section{Ash values}

Total ash value: $2.7 \%$ (normal value not more than $12 \%$ ).

Acid insoluble ash: $0.88 \%$ (normal value not more than $2.5 \%$ ).

Aflatoxin test: non-detectable amount.

Anthraquinones test was carried.

\section{Evaluation of the final results of} chamomile

The azulene compounds are reported to possess an anti-allergic and anti-inflammatory property. Also azulene have been reported to stimulate liver regeneration following oral not subcutaneous administrations and the physicochemical tests that mentioned above showed accepted values as approved in the pharmacopoeia, therefore the samples of batch number 3311 of chamomile which collected from the private pharmacy garden in Tripoli are obey the roles of pharmacopoeial standards and the batch accepted. Our results of the drug investigation are shown as the following:

\section{Organoleptic investigations}

Colour: greenish yellow

Odour: strong and characteristic.

Taste: bitter taste.

\section{Microscopical investigation}

T-shaped and glandular hairs were observed, pollen grains, fibers and 
clusters of calcium oxalates were observed. $^{6-8}$

Extractive values: $0.7548 \mathrm{~g}$.

Heavy metals contaminations

Lead: $0.375 \% \mathrm{mg} / \mathrm{kg}$ (where the normal value in dried herbs 10 $\mathrm{mg} / \mathrm{kg}$ ).

Mercury: 0.0123 ppm (where normal value in dried herbs $1.5 \mathrm{ppm}$ ).

Ash value: $2.1 \%$ ( normal value not more than $8 \%$ ).

Aflatoxin test: non- detectable amount.

Finally we could say that our selected medicinal herbs are complied with pharmacopoeial standards and considered to be safe and effective for use.

\section{REFERENCES}

1- K. Keller, European Phytotelegram, ESCOP, Aug., pp. 40-45.

2- British Herbal Pharmacopoeia, $4^{\text {th }}$ Ed., by the British herbal medicine association (1996).
3- World Health Organization (WHO), EB87.R24 "Traditional Medicine and Modern Health Care", Hbk Res; Vol. III $2^{\text {nd }}$ Ed, $1.15 .4\left(19^{\text {th }}\right.$ meeting, 24 Jan. 1991) (1991).

4- World Health Organization (WHO), "Quality Control Methods for Medicinal Materials", WHO, Geneva, Switzerland (1998).

5- Carol, A. Newall; Anderson, Linda, A. and Phillipson, J. David, "Herbal Medicines", a guide for health- care professionals. London, the Pharmaceutical Press (1996).

6- W. C. Evans, Trease and Evans, "Pharmacognosy", $14^{\text {th }}$ Ed., WB. Saunders Company, LtD, London (1996).

7- William, Charles Evans, "Pharmacognosy", $13^{\text {th }}$ Ed., London (1989).

8- S. Ibrahim, "Atlas in General and Applied Pharmacognosy", $2^{\text {nd }}$ Ed., Tanta University, Press in AbuTabi, Tanta, Egypt (2003).

9- AOAC, Official Methods of Analysis (2000). 